\title{
Power Dynamics of Language and Education Policy in Myanmar's Contested Transition
}

\author{
MARIE LALL AND ASHLEY SOUTH
}

\begin{abstract}
This article examines the development of education policy in Myanmar/Burma at a period of "critical juncture." There are two major strands to this article, regarding policy process and stakeholder voices that we bring together. We argue that powerful actors such as the government and international agencies frame policy in ways that often exclude the concerns and aspirations of education users and that there are often significant gaps between their positions and the realities of "ordinary" citizens. Such issues are of particular concern, given the importance of education and language as key elements of ethnic stakeholders' identities and interests, in relation to the ongoing and still deeply contested peace process. As a result, opportunities opened by the critical juncture in the reform process are being missed. The article is based on data collected in interviews and focus groups with over 500 respondents between 2011 and 2016 in Myanmar.
\end{abstract}

\section{Introduction}

Since 2011, Myanmar has experienced substantial (if still incomplete and contested) transitions across many sectors, including in the field of education. The trajectory of reform has been embedded through the election in November 2015 of a government led by Daw Aung San Suu Kyi's National League for Democracy (NLD). This "critical juncture" (Sonntag and Cardinal 2015) presents historic opportunities for reform but also encompasses risks of exclusion and missed opportunities for transformative change to address the concerns of marginalized groups.

This article questions to what extent ethnic voices are represented in education policy debates within Myanmar's reform process and, in doing so, examines the positions of key stakeholders (ethnic minority communities, civil society groups, ethnic armed organizations [EAOs], government, and international actors). We identify the gaps between the stakeholders and show how issues pertaining to language use and education illustrate the manner in which key elements of the peace process and broader political transition in Myanmar are contested and remain unresolved. Education is of vital concern to many stakeholders in Myanmar, but some positions and voices are more

Received January 28, 2017; revised July 30, 2017, and March 26, 2018; accepted June 4, 2018; electronically published September 7, 2018

Comparative Education Review, vol. 62, no. 4.

(C) 2018 by the Comparative and International Education Society. All rights reserved.

0010-4086/2018/6204-0066\$10.00 
prominent than others. This imbalance reflects broader power dynamics and the privileging of particular interest and identity groups.

That some stakeholders are more powerful than others is not a novel finding. However, the ability of more powerful actors to promote or impose their own values and agendas is problematic in relation to education, where the marginalization of children from ethnic minority and conflict-affected communities is a major concern, as the country strives to achieve "education for all” (Tung 2006) and works toward the United Nation's Sustainable Development Goals (2015) as a part of a wider reform process.

This article discusses two important issues in the domain of education. First, education policy development and peacebuilding seem to be driven by, and delivered to support, the agendas of state actors, which are themselves parties to conflict and the incomplete peace process (International Crisis Group 2016). This is furthermore supported by a development agenda largely driven by international actors. Second, while civil society organizations, political parties, and armed groups may purport to represent local communities, there are often significant gaps between their positions and the realities of "ordinary" people, leading to the former sometimes being positioned as gatekeepers or patrons, mediating the relationship between international and government authority and finance, and local communities. Conflict-affected, marginalized ethnic minority communities are not well represented by either set of political priorities. This results in a missed opportunity and uneven reforms as the ethnic minority communities' values, concerns, needs, and aspirations in relation to education do not match the policies and practices articulated and implemented by the government, international donors and agencies, and other civil society or ethnic minority leaders.

The article briefly explains the marginalization of ethnic minority communities in Myanmar, the reform and peace processes - including education reform - before explaining the research methods used to collect the data and develop the findings presented in subsequent section.

\section{Ethnic Minority Communities and Their Ethnolinguistic Background}

Myanmar is divided into seven states (populated mostly by ethnic minority communities) and seven regions dominated by the majority Burman (Bama) ethnic group. Demographic statistics remain contested, despite a census (the first in 31 years) held in 2014, which calculated the population at 51.4 million people ( 4 million people living abroad as migrant workers and/or refugees). It is estimated that non-Burman communities make up at least 30 percent of the population including Shan (9 percent), Karen ( 7 percent), Rakhine ( 4 percent), Chinese ( 3 percent), Indian ( 2 percent), Mon ( 2 percent), and other (5 percent). ${ }^{1}$ The official categories of 135 "national races" (taingyintha)

\footnotetext{
${ }^{1}$ https://www.cia.gov/library/publications/the-world-factbook/geos/bm.html.
} 
recognized by the government are deeply problematic, representing arbitrary and often imposed identities (Cheesman 2017). Although ethnicity is fluid, subject to reimagination over time and in different contexts, in Myanmar it has become a fixed category and a key element in leveraging access to political and economic resources. The ethnic categorization of society based on both language and race help to orient Burmese politics around divisive and exclusionary categories, creating minority ethnolinguistic groups ${ }^{2}$ that have been marginalized by the Burman dominated establishment. Ethnic minority leaders have long complained of marginalization vis-a-vis the majority community, in the context of decades of armed and state-society conflict and an active campaign of Burmanization since the 1960s (Houtman 1999).

Ethnic minority communities, however, are rarely homogenous in terms of ethnolinguistic orientation or policy preferences, and the ethnic minority diversity extends to intragroup dynamics. For example, there are a dozen Karen ethnolinguistic subgroups consisting of Buddhists, Christians, animists, and Muslims, living around the country. Particular subgroups have sometimes assumed leading roles and reproduced the cultures and languages of heterogeneous ethnic minority groups in the subgroup's own image.

\section{Myanmar in Reform}

Following elections in 2010, Myanmar has gone through a period of transition. Under the leadership of President U Thein Sein, the country experienced widespread if sometimes uneven reforms, including the release of most political prisoners, a greatly improved environment for freedom of speech and association, a resurgence of the social sector, economic reforms, and the start of a peace process between the government and some two dozen EAOs (Lall 2016).

The landslide victory of Daw Aung San Kyi's NLD in the 2015 elections was a watershed moment. Two thirds of the electorate voted for change: out with the reviled military and in with, hopefully, a more accountable and democratic government. The new NLD-led government, which assumed power in April 2016, faces many challenges, including the need for constitutional, education, legal, and land reforms; the need for capacity building in many sectors; further economic reforms; and the challenges of an unfinished peace process. During the first 100 days of its administration, the NLD government completed a number of projects and policies started under the previous government, offering - contrary to expectations - more continuity

\footnotetext{
${ }^{2}$ In Burma/Myanmar studies these groups are not referred to as "ethnic minorities" as they themselves reject this terminology, and the term "ethnic nationality" or simply "ethnic" is preferred. However, for reasons of clarity for an international readership we have agreed to use "ethnic minority" throughout this article.
} 
than change. ${ }^{3}$ Daw Suu herself now heads the peace process, and the NLD government has committed to the previous regime's Nationwide Ceasefire Agreement signed in 2015. Although three Union Peace Conferences have taken place (August 2016, May 2017, and July 2018) to discuss political issues, topics of language and education have received little attention. ${ }^{4}$

\section{Education Reforms}

From the start of the Burmanization process under military rule in 1962, to the election of a civilianized government in 2015, education remained highly centralized, with only Burmese being allowed as a means of instruction. From 2012, the government initiated a Comprehensive Education Sector Review (CESR) spearheaded by the Ministry of Education and supported by international agencies. Others who took part in reviewing education (not in collaboration with each other) included the president's office through the Education Promotion Implementation Committee (EPIC), the Parliamentary Education Promotion Committee, civil society, and student groups. Ethnic education stakeholders were not invited to play a role in the review or reform processes (Lall 2016, 2017). In March 2014, EPIC drafted the National Education Law (NEL) enacted in September 2014, leading to widespread student protests that ended with violent police suppression. The students had a list of 11 demands, ranging from increased government funding of education to the role of student unions in higher education, to ethnic minority languages being used in schools. The NLD, then still in opposition, opposed the new education law but would not endorse student protests. On March 26, 2014, the upper house voted to accept amendments to the National Education Law, without all the changes for which the students had protested (Lall 2016). However, the amendments have allowed for limited decentralization across the education sector, thereby addressing some ethnic concerns. ${ }^{5}$ Education policy under the NLD government has not changed much and is reflected in the National Education Strategic Plan of 2016, which is based on the previous government's draft National Education Sector Plan, focusing on access, completion, quality, and transparency. Ethnic minority languages are now allowed as "classroom language" to help explain concepts when necessary; however, the plan remains silent on the issue of ethnic language as a medium of instruction, and there is no mention of mother tongue-based multilingual education (MTB-MLE). ${ }^{6}$ Thus, ethnic nationality hopes and concerns remain marginalized within debates on education reform in Myanmar.

${ }^{3}$ Anonymous interviews: international government consultants.

${ }^{4}$ Conversations with ethnic minority representatives attending the conference.

${ }^{5}$ The revised NEL 2015 allows the use of ethnic languages, where necessary alongside Burmese (article 43b). The revised curriculum includes a $10 \%$ allocation for local content, which can cover ethnic languages. However, in practice at the time of writing, these changes have not yet been implemented.

${ }^{6}$ MTB-MLE is not presently Myanmar education policy, and using any ethnic language in the classroom effectively would require recruiting local teachers, or teachers who have learned an ethnic 


\section{Ethnic Education}

Since the 1960s, the suppression of minority languages within a centralizing, militarized state intent on the Burmanization of national culture (Houtman 1999) has been one of the main grievances underlying more than half a century of armed conflict. In response, various armed and civilian (civil society and faith-based associations) ethnic actors have developed nonstate minority language education systems (Lall and South 2013; South and Lall 2016a, 2016b). Since the 1980s (and particularly with an influx of external support following the 1988 democracy uprising in Burma), nonstate education regimes expanded, especially in Karen, Mon, and Kachin areas (Lall and South 2013; South and Lall 2016a). These education systems offer MTB-MLE schooling and often support the poorest and weakest across ethnic society. ${ }^{7}$

Despite clear linkages between the ethnic conflict and education reform, the two processes are not formally linked in the peace process. Our respondents told us that the education reforms have left out the voices of ethnic minority stakeholders in conflict-affected areas, creating a mismatch of policy priorities at the local, national, and international level. This highlights gaps between the views of stakeholders on the ground, and the domestic and international actors whose policies are aimed at local communities.

\section{Theoretical Framing}

A key question at the heart of policy making is the extent to which the state determines the process, and as a consequence what room is available for other actors (especially those on the ground) to influence the debate and reinterpret policy texts in practice. In contrast to state-controlled (Gramsci 1971; Offe 1974; Habermas 1991) and state-centered (Dale 1989) explanations of the state's role in policy formulation, Bowe et al. (1992) argue that statecentred models are too simplistic and linear, neglecting the voices of teachers, students and parents. They argue for the need to understand the histories and ideologies of people who receive policy texts. Bowe et al. (1992) stress that the policy process does not begin when policy is launched and received as a text by those who have to implement it but that different stakeholders' voices play important roles throughout the process. An analysis of "voice" in education policy making is particularly salient in today's globalizing world, as the number of actors involved in policy making is increasing, creating a more complex

language. According to UNICEF, 70\% of teachers working in ethnic areas do not speak local languages (Jolliffe and Speers 2016, 37).

${ }^{7}$ More than two-thirds of ethnic minority parents that took part in the research between 2011 and 2016 wanted their children to start their education in their mother tongue and learn the history of the community. Communities that had lived through a long ceasefire thought that learning Burmese was necessary and supported MTB-MLE. Communities in areas of ongoing armed conflict mostly rejected any use of Burmese in their locally run schools and were actively involved in changing the content of the curriculum to remove or reduce dominant Burman influences (South and Lall 2016b). 
playing field. In order to examine whose voice counts, and who gets to define the narrative when discussing Myanmar's education reform, we use the three contexts of the policy cycle, developed by Bowe et al. (1992). Each of the three contexts include public and private arenas of action, and each involves compromise, and in some cases the repression or marginalization of certain interest groups. The application of the three contexts to Myanmar is explained below.

"Context of influence" refers to interest groups' struggle over the construction of policy discourses where key concepts are established. Important networks of influence include relationships between civil servants and ministers, micropolitics within parties, and the roles of unions and education authorities (where these are present). Which voices are heard is crucial. While in Myanmar policy making until 2011 was state-controlled, the reforms under the Thein Sein government allowed a number of new actors to enter debates; in education in particular, development partners that were not influential before joined the fray, including the World Bank, the UK Department for International Development (DFID), and the Australian Department of Foreign Affairs and Trade (DFAT, previously AusAID). The context of influence was in part framed by the CESR that allowed for all education matters to be critically reviewed and discussed. In addition, civil society groups started to raise their voices in public policy debates. The rise of the National Network for Education Reform ${ }^{8}$ and the student movement are testimony to a changing context of influence, with an increase in the importance of previously marginalized stakeholders. However, despite the salience of the peace process, EAO education departments remained on the fringe of the policydevelopment process.

"Context of policy text production" refers to how texts represent policies. Texts have to be read in relation to the historical context, the site of production, and in relation to other relevant documents. This context is one of policy compromise and, often, misunderstandings (Bowe et al. 1992). Typically, the texts of policies are developed by technocratic specialists who may have been exposed to some, but not all, voices and do not necessarily take all substantive issues into account. Also, since authors cannot control the meanings of their texts, the process of interpretation and reinterpretation can results in gaps with respect to practice. The textual production of the new education law represented a political battle (Lall 2017) as the president mandated EPIC to take the lead in education policy, reducing the influence of development partners whose voices had been very loud in the CESR. How-

\footnotetext{
8 The NNER, led by Dr. Thein Lwin, has long advocated for democratic and federalized education regimes - previously in close alliance with the NLD but more recently as an independent network and voice. Eleven Myanmar, NNER to Form Joint Committee for Federal Education System (September 5, 2017): http://www.elevenmyanmar.com/local/9293.
} 
ever, development partners were still part of the writing process, bringing in specialists to make sure Myanmar's new policies would be based on what is considered "international good practice." Stakeholders witnessed increased state direction in the writing of the law but not without pushback from civil society, including loud protests on the street. Again, ethnic actors were not part of the context of text production, while better-resourced international actors found ways to insert themselves in the policy debate.

"Context of practice" refers to how policy is subject to interpretation, recreation, and practice on the ground. The implementation of policy often fails to reflect what was originally envisioned, either in the context of influence or of text production. This context is less relevant for Myanmar at present, as the new policies have yet to become embedded.

This article discusses the different voices in Myanmar's education reform process, situating the analysis in the context of influence where the debate on the formulation of the new policies regarding language and education is taking place. Below we outline a typology of stakeholders with different views, focusing in particular on the marginalized voices and positions of ethnic minority stakeholders and conflict-affected communities.

To explain how different agendas and influences come into play within the context of influence, we find it useful to deploy the lens of "critical junctures," a concept developed by Sonntag and Cardinal in discussing the political economy of policy change (Sonntag and Cardinal 2015, 5). Building on Jenson and Philips' (1996) notion of "citizenship regimes," Sonntag and Cardinal propose that "language regimes" represent coalitions of power and interests in the field of language and education. In Myanmar, different language regimes have emerged through decades of conflict, with "coalitions having been formed around strategic language policy choices" (Sonntag and Cardinal 2015, 7), often led by armed groups. In the current situation, various regimes "clash" with each other - in this case, ethnic language regimes clash with the dominant Burmese regime. For Sonntag and Cardinal, hegemonic language regimes are reinforced by selective opening to claims from positions and actors that reinforce dominant narratives. They call this process "linguistic hegemony" $(2015,8)$. Throughout its history, Myanmar has experienced the linguistic hegemony of Burman language and culture, particularly over the past half-century.

The current reform period represents a possible "counterhegemonic" moment, as previously marginalized actors seek to advance positions within the field of education and language use. This fits a pattern described by Sonntag and Cardinal $(2015,9)$, wherein "counterhegemonic challenges expose [existing patterns of domination] and reconfigure conceptions of language

\footnotetext{
${ }^{9}$ Two British education consultants known to us were drafted in for text writing.
} 
in the process. Advocacy is geared toward changing practices and policies ... thereby disrupting power relations and, by implication, state traditions."

Myanmar is in the midst of historic change, constituting such a "critical juncture," with once-dominant elites and other stakeholders struggling to define and promote their positions and articulate their voices. For such counterhegemonic challenges to be successful, the voices of those advocating policy change should be heard and acknowledged. As Liu (2015) argues, changes in language regime during periods of critical juncture are often the result of bargains between elites and government, with previously marginalized groups particularly effective if they can mobilize successfully vis-à-vis the state. In the case of Myanmar, however, the process of language regime change has been dominated by international actors, with civil society groups, EAOs, and other ethnic stakeholders having only limited opportunities to engage on these issues, despite the possible openings presented by the peace process and broader political reform.

\section{Methodology}

Our research aims to answer the question "to what extent are ethnic voices represented in education policy debates within Myanmar's reform process?" We collected the data presented here during fieldwork undertaken between 2011 and 2016, primarily in Karen-, Mon-, and Kachin-populated areas, where ethnic actors have developed the most extensive nonstate education regimes. Both researchers have been working with ethnic minority stakeholders for over a decade and have been advisors to various EAO leaders and administrative departments, before and during the peace and reform process. In particular, we have supported their education departments in their policy formulation and in their engagement with international agencies. Local partners helped assess the risks; on all occasions, informants were told about the purpose of our research and given the choice of opting out. Throughout the fieldwork, we acted as "critical friends" to our respondents, listening to them and promising to have their voices heard through our work. ${ }^{10}$ The originality of our work is based on our access both to ordinary ethnic stakeholders in their communities (including traveling to remote and difficult-to-access locations) and on interviews with more easily accessible ethnic minority leaders and other stakeholders. Our research stretched over 5 years, during the period of "critical juncture." Nevertheless, our findings and analysis are based on our network of contacts (and their respective extensive networks). Given the limitations of time, budget, and the sensitive political situation in conflictaffected areas, a more systematic survey was not possible at this time. It might

\footnotetext{
${ }^{10}$ Our funders were aware that we were conducting a listening exercise to bring marginalized voices to the fore.
} 
be useful in the future to conduct research, using a more systematic sampling framework, in order to compare results with the "baseline" presented here. In the meantime, our research represents the first attempt to address these issues.

Our first round of data collection was in 2011-12, funded by the Open Society Institute, focusing in particular on mapping ethnic minority education systems in Mon and Karen states, where we interviewed and conducted focus groups with 93 people across eight locations, including in jungle and conflict-affected areas. We were able to access these communities through local colleagues who have been instrumental in delivering education services in hard-to-reach places. Schools contacted local families for us to meet. Most meetings were held in schools, but in some cases respondents preferred to meet us at sites where they felt less exposed to scrutiny. We conducted all interviews in the local language with a trained translator.

Further data collection (funded by USAID, as part of their transition support program) happened between 2014 and 2016, across 10 locations in Mon, Karen, and Kachin states, and neighboring China and Thailand, in both government and EAO-controlled areas. We interviewed 150 people and conducted 30 focus groups with 8-10 participants each, as well as larger meetings with stakeholders from EAOs, ethnic education departments, political parties, and local civil society actors. We accessed EAO leaders and other official stakeholders through colleagues active in the peace process ${ }^{11}$ and through the EAO education departments and education community-based organizations (CBOs). In addition, teachers, parents, and students at ethnic schools were either interviewed or took part in focus groups. All meetings were conducted either in the local language or in Burmese with the help of a trained translator. The data collection method was similar to that used in 2011: schools were contacted through our local education (and, in Kachin state, church) contacts and then schools arranged for teachers and families to meet us. Families had to have at least one of their children at that school and to confirm that they were happy to speak to us. The interview and focus group transcripts were thematically coded, and subsequently the findings were validated through a series of five workshops in Mon and Kachin states conducted around 4-6 months after the original fieldwork had taken place. In these workshops, we presented our findings to a group of stakeholders including community and EAO leaders, teachers, and parents, asking them to confirm if this was an accurate representation of their views. The workshops included state education officials, so as to understand better how the Myanmar government is developing education policy in ethnic areas.

\footnotetext{
${ }^{11}$ Between 2012 and 2015 Ashley South worked as a senior adviser to the Myanmar Peace Support Initiative, at the request of the Myanmar government and key EAOs (MPSI 2014).
} 
A further set of data comes from 28 interviews we conducted as a part of a Pyoe Pin (DFID)-funded research project in 2016, which investigated the funding and teacher training challenges faced by nonstate education institutions. This last round of data collection focused on ethnic education providers in very hard-to-reach areas, including northern Shan state, where conflict is ongoing. In that setting, it was too dangerous to meet parents, so only teachers and other official stakeholders were interviewed.

\section{Findings: Typology of Stakeholders in the Context of Influence and Their Perspectives}

The following section examines the positions of key stakeholders in Myanmar in relation to policy debates around language and education. Using quotations from stakeholders and references to the interviews described above, we demonstrate how policy development often fails to take account of the views and realities of marginalized peoples, including ethnic minority actors in general, and particularly conflict-affected communities.

\section{Local Actors}

Local informants included around 200 parents, teachers, and local village leaders who took part in focus groups.

The right to learn in the ethnic mother tongue.- - The aspirations and demands of Mon, Karen, and Kachin communities tend to be expressed through the dual perspectives of the "right to education" and the "right to political selfdetermination." Ethnic minority respondents expressed strong perceptions and experiences of the suppression of minority languages and cultures on the part of a Burman-dominated state: "Ethnic people don't have rights to learn their own languages in school, and so the majority community dominates us ... government doesn't want to let ethnic people study their own languages" (July 2015). We heard similar views expressed in each focus group by local people, from within all three of the internally diverse ethnic nationality communities visited. ${ }^{12}$ Ethnic people feel discriminated against as their cultures and languages have not been included in the official state curriculum.

More than three quarters of our interlocutors across the three ethnic nationalities talked about the strong relationship between using ethnic languages in education and pride in and maintenance of ethnic identity. Mon villagers (July 2015) gave a number of reasons for choosing Mon national schools: "because we want [our children] to learn Mon, as well as English and

\footnotetext{
12 The only variation between the three groups was in how the role of Burmese language in schools was seen, which related directly to the state of conflict in that particular state (see South and Lall [2016a, 2016b] for an analysis of how levels of conflict affect the acceptance of the Myanmar education system including language).
} 
Burmese; to support our own language and community and nation, otherwise Mon will disappear; because we are poor; because we need to stand in our own land and want our own administration and Mon government; because we want our children to have the same opportunity as others. In the past, we lost the opportunity to learn our own language, and we need Mon national schools to reintroduce our language and culture and build the nation" (various villagers speaking in a focus group).

Language, education, and peace.-Citizens also see their aspiration regarding language use and recognition as part of the larger peace process. For example, around a third of respondents (February 2015; September 2016) pointed out the connection between self-determination in language use, and the broader theme of political self-determination and ethnic nationality leaders' political struggle for federalism in Myanmar. A Mon villager said "we want MTB education in order to preserve and promote our national survival and identity; this is our basic right. If the government wants peace, then they must recognize ethnic languages as part of the federal political solution for Myanmar. In the Mon National Schools, we can learn real Mon history, and students can know and maintain their national identity" (May 2015).

A Kachin villager in northern Shan state emphasized: "for peace to work, the government will need to allow us [communities] to make their own choices" (September 2016). At least a third of the local stakeholders taking part in focus groups complained that their views were not taken into account and their voices could not be heard. The armed struggles of EAOs for selfdetermination were presented by more than half the respondents in terms of the preservation and protection of ethnic communities' identities and languages.

The role of the state.-Local reality, however, means that the government remains the largest provider of education services, even in ethnic states, and the peace process has expanded government provision in previously conflictaffected areas (Lenkova 2015; World Education/KED 2016). A view expressed in over two thirds of the villages visited was that "we don't like having a government school in the village, but we are under control of the military [government] so we have no choice. We don't really want to learn Burmese, but because of the military government we have to" (Kachin, September 2016). The expansion of government provision has also resulted in the "flipping" of some community or EAO schools, which are required to become government institutions, displacing local teachers and reducing or eliminating education in the mother tongue (World Education/KED 2016). A Karen educator said "we are very concerned that the government is using the peace process to push into our areas by building schools" (December 2016). These "takeovers" by the state are perceived as forced convergence, something all ethnic respon- 
dents rejected and feared, not least because it would devalue their own teachers and result in a loss of teaching and learning in the local mother tongue.

Whether intended or not, these developments have contributed to a gap between the concerns and aspirations of communities, and what the government and the aid agencies have sought to achieve, with negative consequences for community perceptions of the peace process. This is often seen as a vehicle for government domination (World Education/KED 2016), thus underscoring the importance of bringing otherwise marginalized voices into policy debates regarding education.

\section{National-Level Nongovernment Actors}

These actors include a wide variety of groups, such as ethnic armed organizations, community-based organizations (some linked to EAOs), nongovernment organizations, and ethnic political parties. Some are active only at local levels, but the peace process has brought the EAOs into national-level policy debates.

The right to learn in the ethnic mother tongue.-Armed group leaders promote mother tongue education as a political aim, framing it as a means to maintain ethnic nationality identity and dignity. As expressed by a Kachin EAO leader: "we want to legally use our language and build our own schools and universities, to study our own philosophy and literature" (July 2015). A senior Karen educator from an EAO expressed similar sentiments, talking about the importance of education in the Karen people's struggle for dignity and self-determination, in the context of cultural assimilation on the part of a state dominated by the Burman majority (September 2016). More than half also see a parallel system of education as a response to Myanmar's poor quality government schools and as a means for their children to have better life chances. This is particularly the case for Kachin communities. In Mon areas, ethnic schools are usually of lower quality than government schools, although children often learn better as they can understand the teachers.

It is important to note that EAO leaders' agendas do not necessarily represent the concerns and aspirations of ordinary communities, which themselves are often highly diverse. Ethnic political leaders often act as gatekeepers, having privileged access to state authorities and international donors. Such well-placed actors can represent their interpretation and framing of ethnic nationality/minority communities' priorities to the international actors as well as frame and represent international patronage to communities, particularly those in difficult-to-reach, remote and often conflict-affected areas. While the views of ordinary villagers and local leaders often coincide, ethnic leaders may have a sociopolitical agenda, especially in areas of ongoing conflict such as Kachin state, where the violence has helped galvanize a fragmented community around a single language (Jingpaw) and a political agenda 
that may leave out subnational groups with different languages and historical experiences. The (Catholic) head of a Kachin higher education college run by an EAO observed that often "the priorities of the Baptist community dominate and the Catholic community can feel marginalized" (February 2016). Similar dynamics play out in the Karen context, where a disproportionate number of leaders are Sgaw-speaking Christians who have dominated the discourse and proceedings of the nationalist movement. Consequently, this dialect is the main "mother tongue" used in conflict-affected areas, even though there are other communities wanting their "mother tongue" used and recognized (December 2016).

Myanmar-wide NGOs have not been successful in bringing the voices of ethnic communities into debates around the development of language and education policies. Only one NGO (Shalom) undertook research and developed policy-advocacy materials in relation to MTB education (Htin Zaw 2011) to "show the suffering of the local children who cannot understand their teachers" (July 2013). Local NGOs have been more directly involved in education provision. One example is a set of community-run schools in Kachin and northern Shan states, funded and managed by a Kachin CBO with international support. Local Kachin educators wanted a different model than state education, which is perceived as highly authoritarian and ineffective, and so are developing their own: "de-coupled from the government system, until the state system undergoes significant reform"-which is not seen as likely any time soon (December 2015; September 2016). This project is presented as a "community transformation initiative," based on ethnic languages and locally owned, while also not linked to an EAO. The schools themselves are funded through fees, and parents reportedly have no interest in preparing students for government exams.

Language, education, and peace.-Although armed group leaders often have positions on issues of language and education, these have only received limited attention in the peace process, which raises questions about the priorities of those sitting at the table. Civil society groups and leaders' positions also do not always represent the views of local communities, but are nevertheless important, as they serve as markers for the international agencies, including with regard to language and peace. As a prominent Kachin community leader and development worker said (June 2015): "ethnic education can fuel conflict, or can be part of the healing process. . . . We learn to be protective, including of our identities, because we are insecure. The international community must understand that unless ethnic issues are addressed, there will be no real peace in Myanmar." A Mon civil society representative put this particularly strongly: "If Burmese leaders ignore mother tongue language issues and the voices of ethnic people, then ethnic nationalities may choose to leave the Union; there is no trust in the government" (July 2015). Given 
this very strong feeling among all respondents, it is the responsibility of EAOs to bring these issues to the policy table, not leaving it to the Myanmar government to make the decisions top-down as has been done in the past. As a Mon political activist (July 2015) reminds us: "All ethnic people are trying to get MTB teaching in schools, but the government hasn't allowed it because of their policy of Burmanization and centralization; they want everyone to speak Burmese. If Burmese leaders ignore federalism, the Civil War will never stop." Karen politicians and activists have also repeatedly called for a federal political settlement to Myanmar's long-standing state-society and ethnic conflicts (December 2016).

The role of the state.-Other national actors include ethnic political parties that emerged out of the 2010 elections, which campaigned vigorously-but not very successfully - in the 2015 polls. Previous research shows that between 2011 and 2015 a number of ethnic political parties were able to develop relationships with ethnic minority communities on a rather different basis than that established over the years by EAOs (Lall 2015). Leaders from some ethnic parties managed for the first time to bring ethnic minority concerns to national-level politics through the state and union parliaments. Although not much attention was paid to these concerns at the center, and the $\mathrm{U}$ Thein Sein-government kept ethnic parties on the sidelines in relation to the peace process, this did not prevent them from working on what they perceived as ethnic minority priorities at state level. One of the most successful examples is Mon state, where the All Mon Regions Democracy Party (with two ministers in the Mon state government) spearheaded the push for Mon being taught as a subject in government schools, something that engendered the ethnic language debate in other ethnic states. The state government now pays a modest stipend for Mon language teachers in state schools. While this still does not meet the aspirations of parents who want MTB-MLE, it was nevertheless seen as a major achievement for ethnic parties and state-level politics.

Government and International Actors

The right to learn in the ethnic mother tongue.-According to local actors, the expansion of government education provision in former conflict areas in the context to the peace process is problematic. While increasing access to, and greater resources for, education is generally welcomed, the state is still regarded with great suspicion. The government does not allow mother tongues to be used as medium of instruction in schools, although the newly published National Education Strategic Plan does allow teachers to explain concepts in the ethnic language in the classroom when necessary.

Language, education, and peace.-State education actors, and government officials more widely (including the leadership of the NLD), seem not yet to 
grasp the link between MTB-MLE in schools and minority citizens' aspirations for respect, and the recognition and reproduction of their languages and cultures, which is why the issue of language and education is absent from the peace process. A discussion with the head of the CESR (also an MoE official) showed that keeping Burmese as a Union language was seen as critical: "You see in that meeting we just had, we all could communicate because we all have learnt Burmese. No matter if you are Mon, Shan, Kachin or other you can speak to any other ethnic because of Burmese. So it is essential they learn Burmese in school" (July 2013). There is a significant gap between government policy and the aspirations of local ethnic minority communities, who see the use of their language in schools as a vital part of sustainable peace.

The role of the state.-At the policy level, the government remains the most important national actor in education/ language debates, especially given that it leads the reform process. It is therefore noteworthy that the education reform agenda has been largely dominated and driven by international agencies. While the U Thein Sein-government tried to reduce the influence of international actors, domestic nonstate actors had only limited influence on how education law and policy was implemented between 2010 and 2015 (Lall 2016).

The reforms have brought in new international actors, who are now very much part of all three policy contexts. Prior to 2010, only UNICEF and the Japan International Cooperation Agency worked with the government on education issues. With the opening up of the country since 2011, key international agencies such as the World Bank, Australian DFAT, DFID and others have started to support the government both through financing and with policy formulation. The main vehicle for this was the CESR; however, international agencies had little or no access to ethnic minority stakeholders (September 2013, July 2014) and therefore did not push for the CESR to take views from conflict-affected areas into account.

The role of international aid for education raises questions about the influence that foreign assistance has on national education policy making and planning. Steiner-Khamsi (2004) talks about the concept of policy borrowing and lending in education, where reforms are transferred from one country to another as "best practices." The phenomenon of transfers and travel has increased considerably as a result of globalization.

One example of policy borrowing with direct impact on ethnic minority populations (demonstrating the gap between international actors and the local communities they claim to serve) was the series of workshops (FebruaryJuly 2014) run by UNICEF as part of a multicountry process focused on developing proposals for ethnic language policy in schools as part of a larger social cohesion agenda. This process included workshops in some of Myanmar's seven ethnic states, with stakeholders selected by UNICEF. The result- 
ing "Nay Pyi Taw Principles" encourage the government to teach the mother tongue in government schools. Given the legacy of forced integration and Burmanization agendas in Myanmar, this was certainly a step in the right direction. However, this program largely failed to meet the demands of the ethnic minority communities, who generally want MTB-MLE education, not just the inclusion of ethnic minority languages as a taut subject in government schools. Participants in the UNICEF-led process were largely co-opted ethnic leaders, with the project perceived by many ethnic minority stakeholders as driven by external agendas, with a restricted timescale. ${ }^{13}$ Those whose views differed with UNICEF were not part of the discussions, with one stakeholder stating: "We do not agree with this top-down process, and we refuse to take part in something that promotes the government's view" (December 2015). Furthermore, the name and logo of a leading ethnic NGO was used by UNICEF to promote an international conference supporting the NPT Principles, although this NGO was actually opposed to the principles (December 2015). It appears that, in this example at least, local voices are filtered in accordance with preset agendas that are then validated through selective use of local stakeholders. Nevertheless, this UNICEF-led project did go some way toward raising awareness of ethnic minority language and education issues in government and international donor circles.

Overall, the international aid agenda in the field of education seems to be increasingly driven to support the government priorities, to the detriment of nonstate ethnic provision. ${ }^{14}$ This has been the case since the onset of the CESR and has increased since the NLD took power. When discussing the future of ethnic education, the main international agencies have often pushed ethnic schools and systems to "converge" with the government system, arguing that this is the best way forward in terms of meeting teacher salary needs and making sure that children can transition to secondary school and university smoothly (March-July 2013; October 2014). One international education expert working at an embassy emphasized: "How can these ethnic schools keep funding themselves? They have run out of money to pay their teachers. It is better if they just join the government. We have to convince them" (July 2013).$^{15}$ While certain ethnic minority education systems find it difficult to maintain a parallel system now that their funding is drying up, more than two

\footnotetext{
${ }^{13}$ For more information on the dialogues and who was invited, see chapter 6 of the Myanmar Synthesis report: https://www.unicef.org/eapro/MYANMAR_Country_Report_ReportLanguage_Education _andSocial_Cohesion_Initiative_.pdf.

${ }^{14}$ In 2013 key donors to education in Myanmar (Australia and UK) established the Myanmar Education Consortium (MEC), to support nonstate education. At least until 2015, our respondents told us that they found the MEC unresponsive to their realities and needs.

15 The leading international aid actor in education in 2014 hired an international consultant to access ethnic minority communities and understand their concerns better. Once contact had been made the leading diplomat went out of her way to try to convince the ethnic minority leaders she met that they should converge with the government system, creating an angry reaction.
} 
thirds of those we spoke to see convergence as dangerous unless terms to protect teachers and language of instruction are agreed upon. The "flipping" of schools (discussed above) and support to government-driven policies by leading international actors shows that local voices are being ignored.

\section{Discussion: The Context of Influence at a Critical Juncture}

The positions of the three sets of stakeholders are different, making their interactions in the context of influence particularly interesting. Because of the gaps between actor positions and policy outcomes, the opportunities of Myanmar's "critical juncture" are being missed.

The context of influence in Myanmar's ongoing debates regarding language and education policies is marked both by an education reform agenda that seems to be co-driven by the international actors, and by a separate peace process that is driven by EAOs, and the Myanmar government and the army. ${ }^{16}$ Both processes have opened the political space for radical change - a "critical juncture," with the prospect of moving toward a more participatory system, taking account of ethnic minority aspirations. New stakeholders have entered the discussions, including EAOs and a range of diverse civil society actors. However, ordinary voices from ethnic, conflict-affected areas have been underrepresented in relation to those of the central state and donor community, with the result that communities seem unlikely to get MTB-MLE anytime soon.

The problem is compounded by the changing role of ethnic civil society within this critical juncture. Daw Suu seems to expect the country's civil society actors to follow the government's lead in social and political matters, or join political parties. Ironically, NGOs and CBOs had more influence under the previous military-backed, transitional government (Fink and Simpson 2017). Already, there is discernible unease among some CBOs and activists who had assumed the new government to be a natural ally in the cause of democratization but now fear that their room for action and activism will be curtailed by a regime they had struggled to install.

The realities, aims, and objectives of government, development partners, and ethnic leaders often do not reflect the views and realities of the conflictaffected populations. Local demands, as detailed by our research, differ more from the agenda of international actors than from local civil society-although there are gaps there as well. As a result, despite recent counterhegemonic movements and moments on language in education, local voices are not being sufficiently heard. This is particularly the case regarding the debate on which language should be used in schools, what role the mother tongue

\footnotetext{
16 There are numerous, well-documented examples of the Myanmar Army disrupting education in ethnic minority-populated areas of Myanmar, often as part of brutal counterinsurgency strategies; see, e.g., Smith (1999), MPSI (2014), Lenkova (2015), World Education/KED (2016).
} 
should play, and at what point the union language (Burmese) should be included in ethnic education. This debate also includes questions such as what, if any, relationship the EAO education departments and individual schools should have with government education authorities, and the status and future of nongovernment schools and teachers. Part of the problem is the difficulty EAOs and ethnic civil society organizations face in developing clear policy priorities in a fast changing scenario, while government and donors resist EAOs' (often weak) articulations of ethnic demands. In the absence of clearly articulated positions on the part of ethnic stakeholders, and opportunities to present these positions, the government and the international agencies are unlikely to recognize the priority that many ethnic minority stakeholders accord to developing the right policies in relation to education and language. Indeed, there is a risk that the failures of ethnic minority stakeholders to develop clear and coherent positions within and between different groups could allow the government (with the support of the international agencies) to "divide and rule," moving ahead with its own priorities in the face of what could be portrayed as an inconsistent and fragmented set of ethnic stakeholders.

Myanmar is left with policy debates that represent the views and agendas of international and national (and to a lesser degree, local) elites, with a widening gap regarding the needs, wishes, desires, and realities of local communities. As with the previous government, there is a peace process where discussions between EAOs and the government do not prioritize education and language issues, and a disconnected education reform process that does not recognize the ethnic education structures that have emerged out of decades of conflict (South and Lall 2016b). This indicates the new government's lack of prioritization regarding ethnic issues.

Similarly, the critical juncture for addressing the root causes of conflict and creating real peace risks being missed. Worrying examples of heavyhanded government initiatives, which seem to demonstrate a lack of awareness and respect for ethnic stakeholders, included the clumsy and divisive appointments of a Mon minister for ethnic affairs, and the imposition of NLD chief ministers in Shan and Rakhine states, despite the NLD's failure to win a majority in these provincial assemblies. ${ }^{17}$ Daw Aung San Suu Kyi seems to continue the long-standing practice of Burmese central government leaders co-opting the participation of mostly male ethnic minority leaders to implement agendas and programs decided by a small cohort of urban-based, generally Burman leaders behind closed doors, rather than engaging systematically with local stakeholders.

\footnotetext{
${ }^{17}$ Under the 2008 constitution, state and region chief ministers are appointed by the president. The new government appointed Mon National Party (MNP) vice-chairman Nai Thet Lwin as ethnic affairs minister without consulting the Mon party. This infuriated other MNP leaders, who felt insulted by the lack of consultation (Aong 2016).
} 
The ability of stakeholders to be heard in policy debates and have their interests and identities reflected in program design indicates different actors' relative power and clearly indicates that those most affected by the policies have the least say in their development.

These findings are relevant beyond Myanmar. In other ethnically diverse countries, issues of language and education are central to identity-driven conflicts. Examples in the region include northeastern India, southern Thailand, and the southern Philippines (Mindanao). The latter two contexts in particular would benefit from a sympathetic understanding of ethnic (and religious) minority communities' grievances and aspirations in relation to perceived domination by the majority community, associated with the central state. Only when minority positions are taken into account in reforming education and language policies will state structures be perceived as legitimate on the part of marginalized, conflict-affected committees.

\section{Conclusion}

Myanmar is at a "critical juncture" (Sonntag and Cardinal 2015). Although this presents an opportunity for marginalized stakeholders within the fields of education and language policy to have their voices heard and their aspirations and concerns addressed, our research indicates that policymaking dynamics in Myanmar continue to favor mainstream stakeholders, including the donors. These power imbalances have existed within the field of education and language for at least six decades, since the advent of military rule, and reflect broader tensions and inequalities in state-society relations in the country. Our findings indicate that the peace process has largely failed to engage with issues of language and education policy, while education reforms have generally not addressed the aspirations and concerns of ethnic minority communities. In the meantime, a default government policy (supported by international agencies) of expanding state education systems into ethnic minority-populated areas risks undermining conflict-affected communities' trust in the peace process. In part, this derives from the unreflective adoption among donors and governments of a "failed state" framework in relation to Myanmar, according to which the main challenge is how to strengthen and expand the reach of the government and its services. As explained in this article, we believe this is a faulty analysis and unhelpful approach and is unlikely to result in the development of equitable language and education policies.

\section{References}

Aong, Jaeneh. 2016. "MNP Vice-Chair among 18 Ministerial Nominees." Mon News Agency, March 22, http://monnews.org/2016/03/22/mnp-vice-chair-among-18-min isterial-nominees-2. 
Bowe, Richard, Stephen Ball, and Anne Gold. 1992. Reforming Education and Changing Schools. London: Routledge.

Cheesman, N. 2017. "How in Myanmar 'National Races' Came to Surpass Citizenship and Exclude Rohingya." Lournal of Contemporary Asia 47 (3): 461-83.

Dale, R. 1989. The State and Education Policy. Berkshire: Open University Press.

Fink, Christina, and Adam Simpson. 2017. "Civil Society." In Routledge Handbook of Contemporary Myanmar, ed. A. Simpson, N. Farrelly and I. Holliday. London: Routledge.

Gramsci, Antonio. 1971. Selections from the Prison Notebooks. New York: International.

Habermas, Jurgen. 1991. The Structural Transformation of the Public Sphere: An Inquiry into a Category of Bourgeois Society. Cambridge, MA: MIT Press.

Houtman, Gustaaf. 1999. Mental Culture in Burmese Crisis Politics: Aung San Suu Kyi and the National League for Democracy. Tokyo: Institute for the Study of Languages and Cultures of Asia and Africa.

Htin Zaw, Harry. 2011. "Shalom Ethnic Education Research in Ethnic Areas.” English summary of a Burmese document not in the public domain.

International Crisis Group. 2016. Myanmar's Peace Process: Getting to a Political Dialogue. Briefing no. 149, International Crisis Group. https://www.crisisgroup.org/asia/south -east-asia/myanmar/myanmar-s-peace-process-getting-political-dialogue.

Jenson, Jane, and Susan Phillips. 1996. "Regime Shift: New Citizenship Practices in Canada." International Journal of Canadian Studies 14 (Autumn): 111-35.

Jolliffe, Kim, and Emily Speers. 2016. Strength in Diversity: Towards Universal Education in Myanmar's Ethnic Areas. San Francisco: Asia Foundation.

Lall, Marie. 2015. Myanmar's Ethnic Parties and the 2015 Elections. Yangon, Myanmar: European Union.

Lall, Marie. 2016. Understanding Reform in Myanmar, People and Society in the wake of Military Rule. London: Hurst.

Lall, Marie. 2017. "Education-A Renewed Political Battleground." In The Routledge Handbook of Contemporary Myanmar, ed. A. Simpsom, N. Farrelli, and I. Holliday. London: Routledge.

Lall, Marie, and Ashley South. 2013. "Comparing Models of Non-State Ethnic Education in Myanmar: The Mon and Karen National Education Regimes." Lournal of Contemporary Asia 44 (2): 298-321.

Lenkova, Polina. 2015. Conflict Sensitivity in Education Provision in Karen State. Yangon, Myanmar: Thabyay Education Foundation.

Liu, Amy. 2015. "The Politics of Language Regime: A Comparative Analysis of Southeast Asia." In State Traditions and Language Regimes: Conceptualizing Language Policy Choices, ed. Selma K. Sonntag and Linda Cardinal. Kingston: McGill-Queen's University Press.

Myanmar Peace Support Initiative. 2014. Lessons Learned from MPSI's Work Supporting the Peace Process in Myanmar, March 2012 to March 2014. Yangon: Myanmar Peace Support Initiative.

Offe, Claus. 1974. "The Capitalist State and the Problem of Policy Formulation." In Stress and Contradiction in Modern Capitalism: Public Policy and the Theory of the State, ed. Leon N. Lindberg, Robert Alford, Colin Crouch, and Claus Offe. Chicago: University of Chicago Press.

Smith, Martin. 1999. Burma: Insurgency and the Politics of Ethnicity. 2nd ed. London: Zed. 
Sonntag, Selma, and Linda Cardinal, eds. 2015. State Traditions and Language Regimes: Conceptualising Language Policy Choices. Kingston: McGill-Queen's University Press.

South, Ashley, and Marie Lall. 2016a. "Language, Education and the Peace Process in Myanmar." Contemporary Southeast Asia 38 (1): 128-53.

South, Ashley, and Marie Lall. 2016b. Schooling and Conflict: Ethnic Education and Mother Tongue Based Teaching in Myanmar. San Francisco: Asia Foundation.

Steiner-Khamsi, Gita, ed. 2004. The Global Politics of Educational Borrowing and Lending. New York: Teachers College Press.

Tung, Ko-Chi. 2006. "EFA Mid-Decade Assessment." Paper presented at the 7th National EFA Coordinators Meeting, Bangkok. http://unesdoc.unesco.org/images /0014/001453/145310e.pdf.

United Nations. 2015. Sustainable Development Goals. http://www.un.org/sustainable development/sustainable-development-goals/.

World Education/KED. 2016. School Committees and Community Engagement in Education in Karen State. Washington, DC: USAID. 